\title{
RENAL CELL CARCINOMA IN 20 YEARS OLD FEMALE; A DIAGNOSTIC DILEMMA
}

\author{
RAVI ROSHAN KHADKA ${ }^{1}$, MD. SAJID HASAN ${ }^{1}$, MD. SHAFIQUR RAHMAN ${ }^{1}$, A.S.M SHAFIUL AZAM ${ }^{1}$, \\ SANJEEB BHAKTA BISTA ${ }^{1}$, MD. MOSTAFIZUR RAHAMAN ${ }^{1}$, ATM AMAN ULLAH ${ }^{1}$
}

${ }^{1}$ Department of Urology, BSMMU, Dhaka

\begin{abstract}
A 20 year old female was diagnosed, clinically, radiologically and by FNAC as a case of benign renal mass. She was observed for 5 months and on reevaluation by contract enhanced CT scan of abdomen revealed, contrast enhancing well demarcated mass with stable size. She was then planned for enucleation and frozen section biopsy. Per operatively, mass were easily enucleated but frozen section shows malignancy hence nephrectomy was done. Histopathological report showed; renal cell carcinoma, clear cell type and TNM staging; T1b Nx MO. Hence in this paper, we have reviewed the article regarding $R C C$ in young age and a diagnostic dilemma of RCC in young age.
\end{abstract}

Bangladesh J. Urol. 2018; 21(1): 43-47

\section{Introduction}

Renal cell carcinoma (RCC) accounts for $2 \%$ to $3 \%$ of all adult malignant neoplasm .RCC is primarily a disease of older adults, with typical presentation between 50 and 70 years of age and male-to-female predominance of 3: 2. However, diagnosis of RCC has increased more rapidly in those less than 40 years of age (young adult) (1). The incidence of RCC in young adult is about $3.4-7.5 \%$ and Sex ratio $(\mathrm{M} / \mathrm{F})$ at age $<40 \mathrm{yr}$ is 1.2 $(2,3,4,5,6)$. RCC in young adult is biologically and histologically different from RCC in older adult and also have different clinical behavior and long term outcome.(6)

Sometime the dilemma remains in the inability to confidently differentiate between RCC in young adult and renal oncocytoma, fat poor angiomyolipoma and renal pseudo tumor on clinical or radiological investigations (1). In this paper, we have reported the case of RCC in young female of 20 years where there was dilemma in clinical and radiological diagnosis.

\section{Case report}

A 20 years old, non diabetic, normotensive, mother of a child, presented with episodic dull aching, non radiating right loin pain for 6 months. Pain was mild to moderate in intensity that aggravates by movement and relieved by medication and rest. She gave no history of haemturia, graveluria, pyuria, fever with chills, cough and hemoptysis, bone pain or weight loss. Her vitals were within normal limit and she was non pallor, non icteric and all accessible lymph nodes were not palpable. Her systemic examination revealed no abnormalities.
Complete blood count was normal except raised ESR (40 $\mathrm{mm}$ in $1^{\text {st }} \mathrm{Hr}$ ) and Urine routine and culture was normal.USG of whole abdomen revealed, Solid mixed echogenic intrarenal mass at mid pole of right kidney measuring about $6.1 \times 3.8 \mathrm{~cm}$ at mid pole (Figure;1).

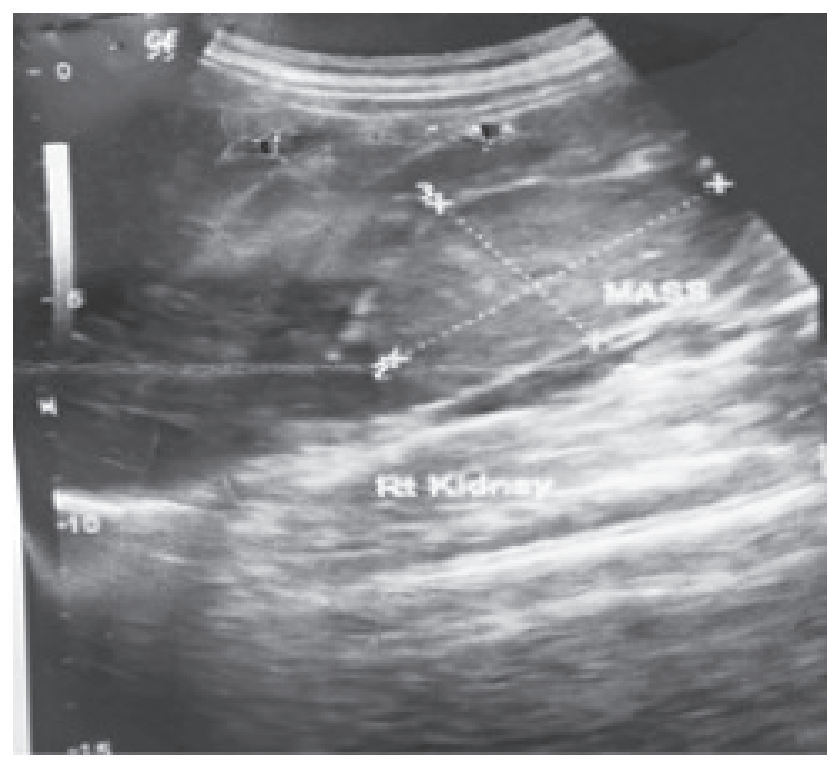

Fig.-1

CT guided FNAC revealed; Negative for malignant cells. Patient was under follow up and further evaluated after 5 months as frequency of pain increases. USG of whole abdomen after 5 months revealed, Solid mixed echogenic intrarenal mass at mid pole of right kidney measuring about $6 \times 4 \mathrm{~cm}$ at mid pole (Figure ;2).

Correspondences: Dr. ATM Aman Ullah, Associate professor, Department of Urology, BSMMU, E-mail address: amanpg@ gmail.com 


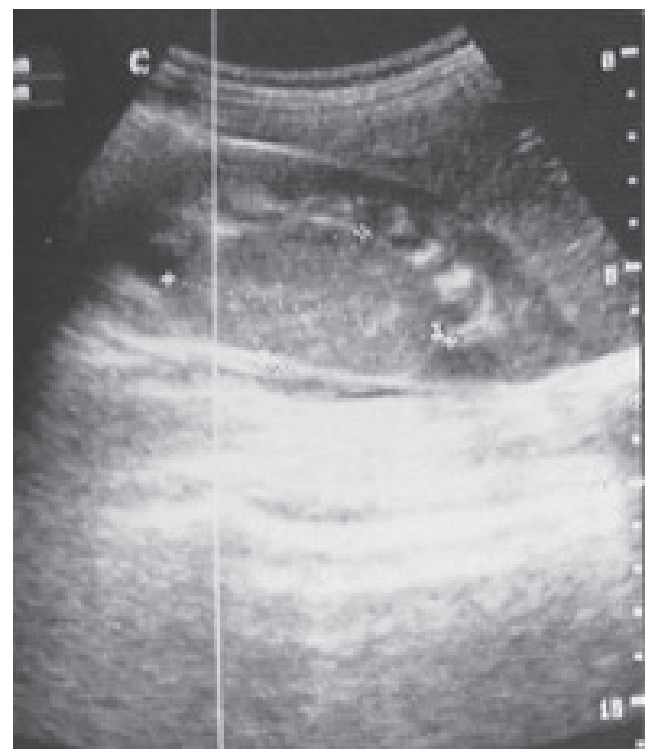

Fig.-2

Contrast enhanced CT scan of whole abdomen on follow up revealed; Well defined, homogenously round, contrast enhancing mass measuring about $6.1 \times 4.1 \mathrm{~cm}$ arising from mid and lower pole along the posterior surface of right kidney. Perinephric fat plane is well maintained, no lymphadenopathy and renal vein is free of tumor. (Figure; $4,5,6)$. Investigations for anesthesia fitness and metastatic evaluation (CXR P/A view, Liver function test including Alkaline phosphatase) were normal.

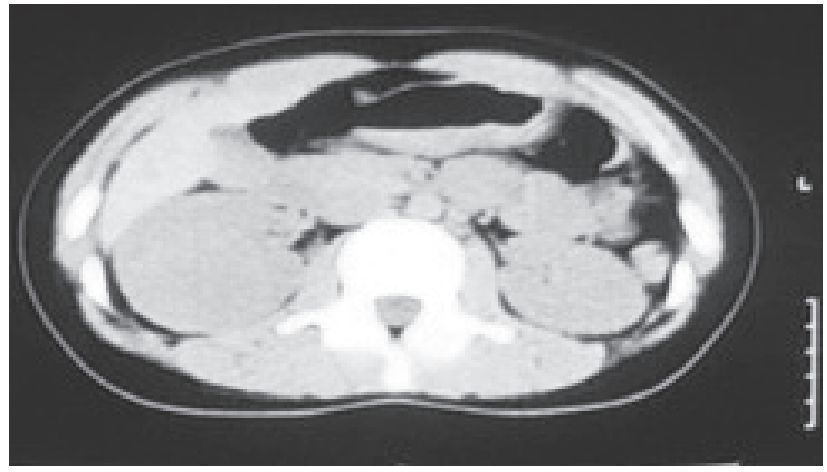

Fig.-3

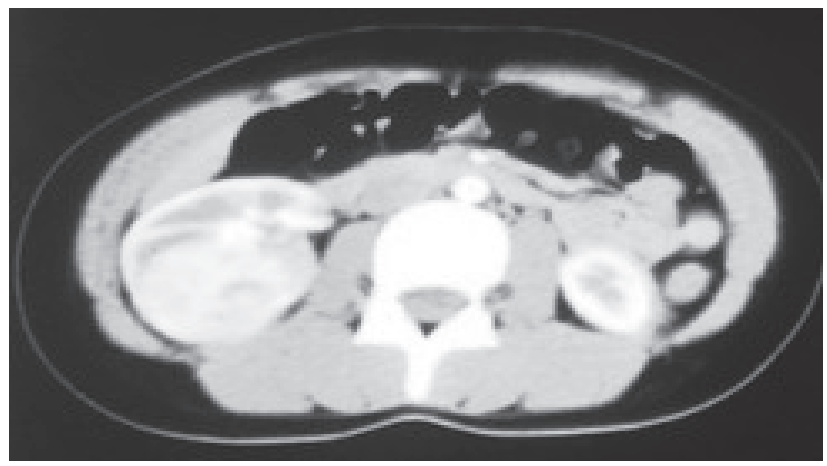

Fig.-4

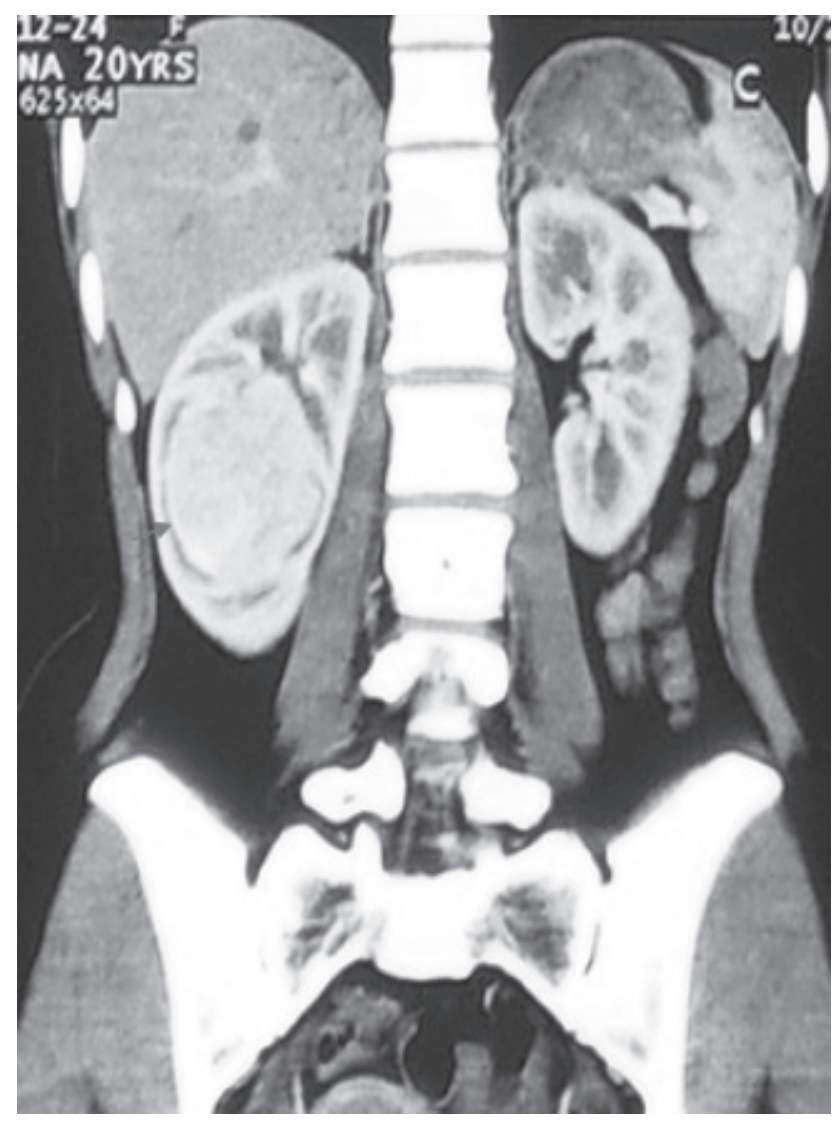

Fig.-5

\section{Clinical diagnosis and planning:}

With the clinical diagnosis of benign right renal mass, enucleation and frozen section was planned under general anesthesia (G/A)

Operative procedure (Enucleation converted to Nephrectomy):

Under G/A with standard surgical painting and drapping, retroperitineum was reached via $11^{\text {th }}$ rib bed incision. Findings were noted; normal perirenal area with no exophytic extention of mass (figure;7). Enucleation was carried out after maintaining cold ischemia (figure; 8,9) Intrarenal mass was enucleated easily by blunt dissection except one place where there was dense fibrosis. (figure; 10,11,12) Mass was sent for Frozen section and haemostasis was maintained and kidney closed by vicryl 2/0.(Figure;13). Perinephric fat patch was placed over wound and waited for frozen section biopsy report (figure;14). Frozen section shows; Positive for malignancy hence nephrectomy was done maintaining haemostasis. Wound was closed in layers with drain in situ.(figure;15 ) 


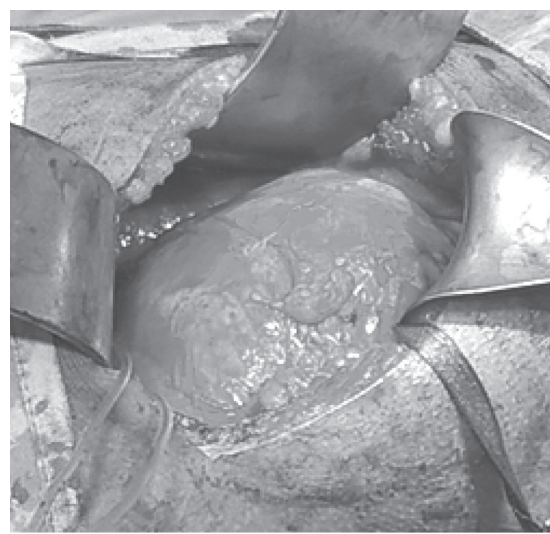

Fig.-7

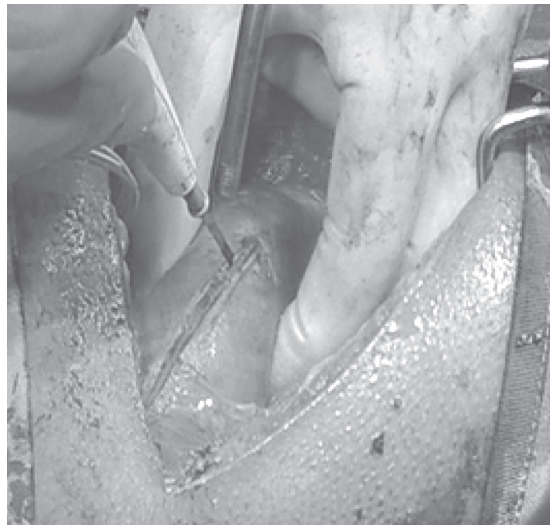

Fig.-10: Enucleation

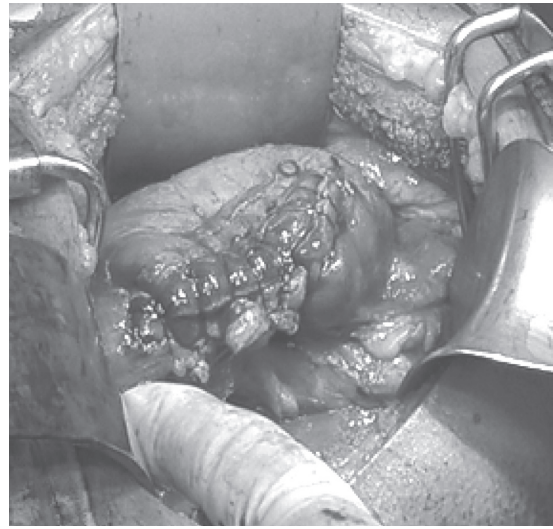

Fig.-13

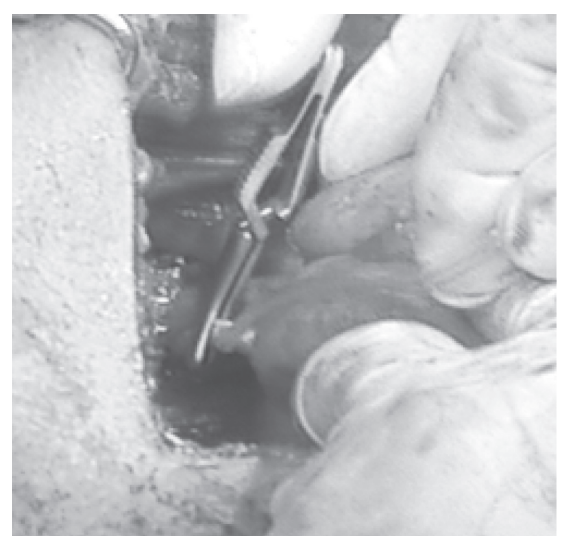

Fig.-8 : Bulldog forceps applied to renal vessels

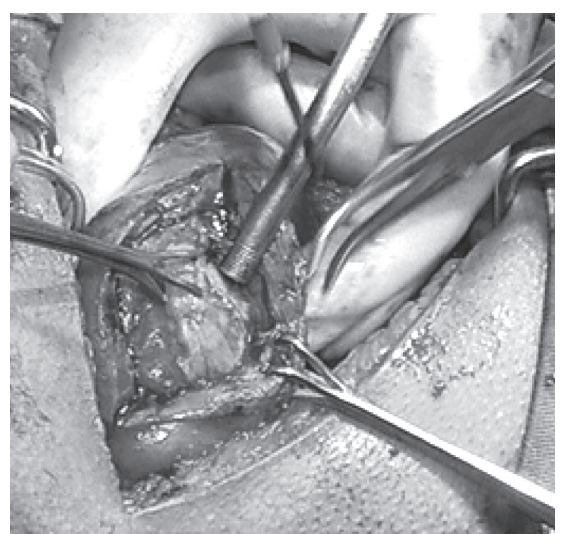

Fig.-11: Enucleation

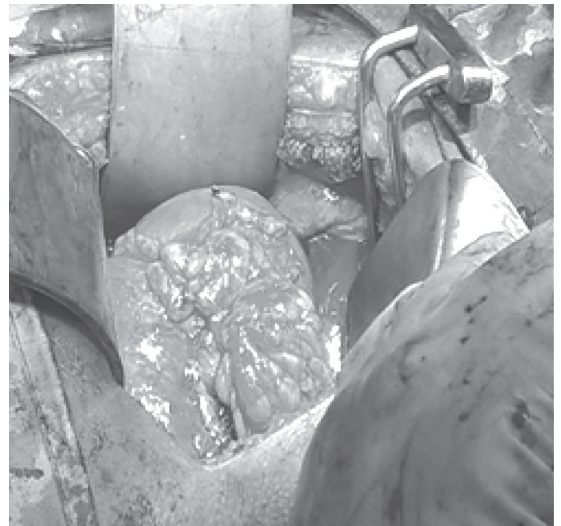

Fig.-14

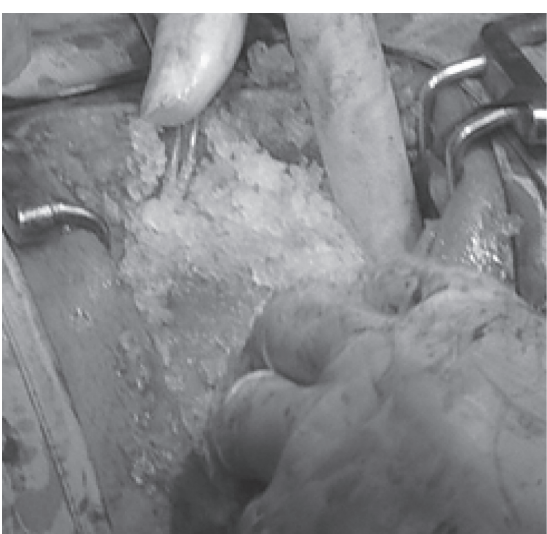

Fig.-9 : Ice slush applied

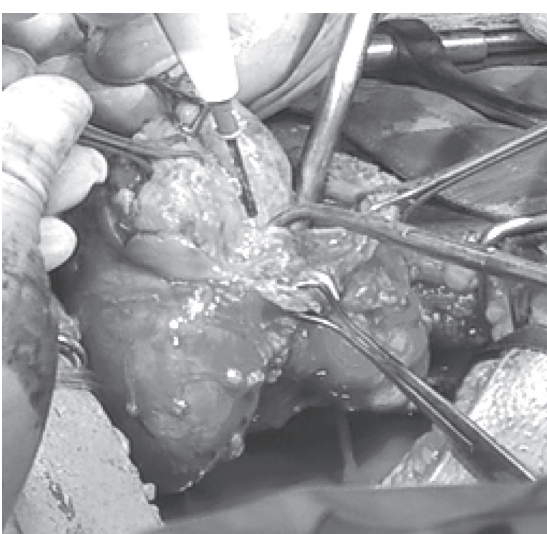

Fig.-12 : Enucleation

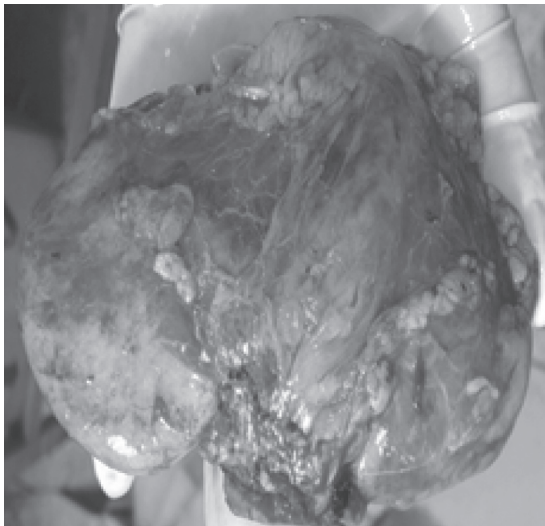

Fig.-15 : Nephrectomy after getting frozen section report
Post operative care and histopathology report:

Post operative periods were uneventful and patient was discharged on $8^{\text {th }}$ postoperative day. Histopathology report revealed; Clear cell RCC $(4.5 \mathrm{~cm}$ in greatest dimension) with Fuhrman grade 3 . No lymph vascular invasion and ureteric margin free. Pathological TNM staging; pT1b Nx Mx. (Pathology board was set to report this case)

Final diagnosis and follow up plan:

Right Renal cell Carcinoma, Clear cell type and TNM staging; T1b Nx M0 .Patient was advised to follow up after 3 months with relevant investigations but patient didn't showed up for follow up.

\section{Discussion:}

RCC typically present at the age between 50 to 70 years and the mean age being 62 years. The incidence of RCC in young adult is about $3.4-7.5 \%$ and Sex ratio $(\mathrm{M} / \mathrm{F})$ at age $<40 \mathrm{yr}$ is 1.2 and $>40$ years 2.5 i.e., female predominance in younger age group (2).Histologically,clear cell carcinoma is the most common type of RCC in young (fewer in compare to old 
age). Young adult have more papillary tumours than older adults[2,5,6,7,8]. RCC in young adult has a better prognosis than older patients as it is more often localised at diagnosis in young adults[2,6,7]. Tumor stage and grade at presentation are the other important determinants for patient's survival[2,7].

Sometime there may be dilemma in clinical diagnosis of RCC and oncocytoma because variants of RCC (Clear cell and chromophobe RCC with eosinophilic characters) may be confusing clinically, radiologically and histopthologically[10,11,12].

Variants of RCC and oncocytoma-Similarities

Presentation; both have a similar age at presentation with peak incidence in the seventh decade with $2: 1$ male-to female ratio. Younger female with renal mass have 2 times chance of having benign neoplasm; mainly AML and Renal oncocytoma[1].

Clinical similarities; both are either asymptomatic or mostly present as flank pain or haematuria. Due to increased diagnostic facilities, now a day most of the RCC are diagnosed incidentally and hence have similar presentation as oncocytoma (usually asymptomatic). $[1,10]$.

Radiological similarities; On CT scan, oncocytomas appear to have a high peak Hounsfield unit (HU) attenuation (similar to RCC); Both are contrast enhancing (Figure 16,17) .RCC can't be differentiated from oncocytoma by T2-weighted images on MRI. The growth rates of both tumors are similar for the patients who are under surveillance hence growth kinetics also do not help differentiate these tumors $[1,10]$.

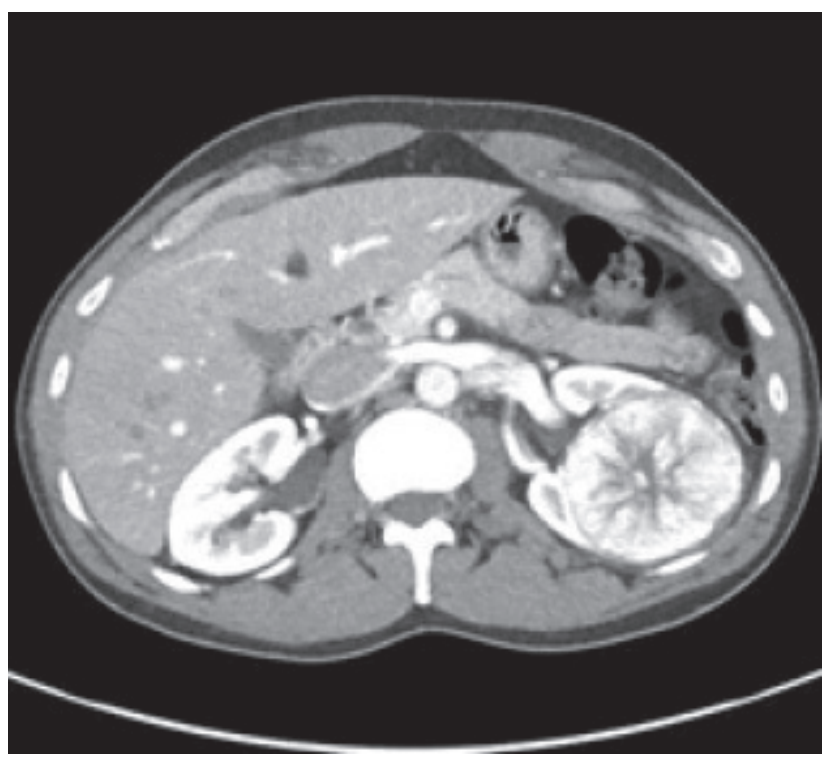

Fig.-16: Renal oncocytoma

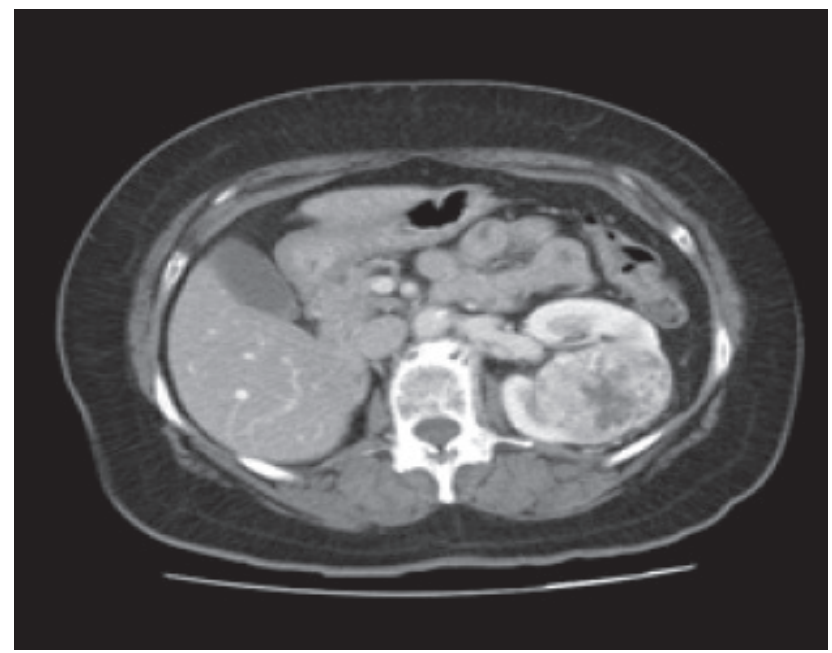

\section{Histological similarities}

Histologically, it is very difficult to differentiate oncocytoma from clear cell RCC and chromophobe RCC with eosinophilic characteristics[1,9].

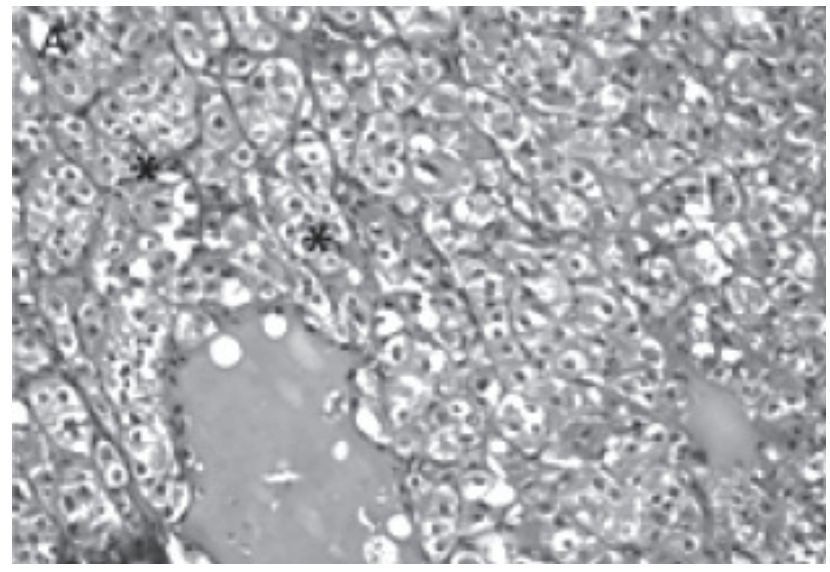

Fig.-17: $R C C$

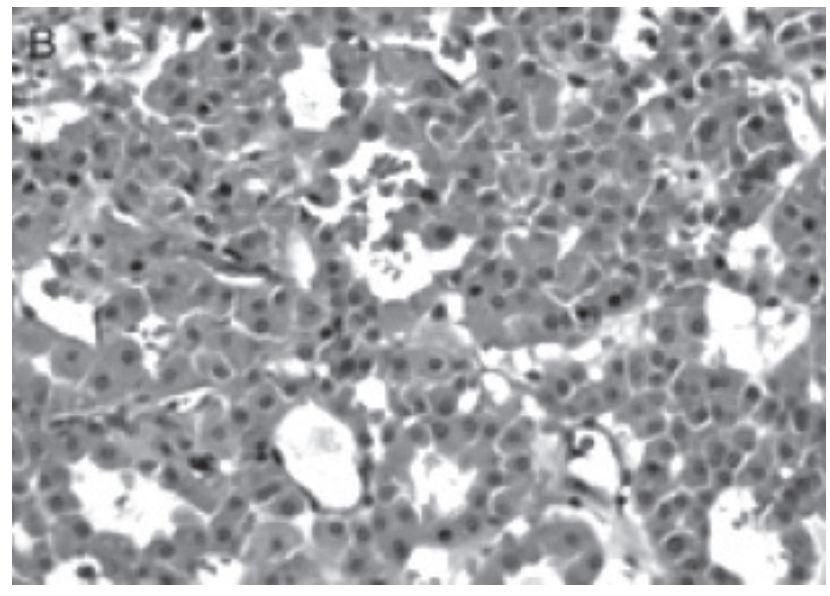

Fig.-18: Chromophobe RCC with eosinophilic variant (1) 


\section{Some differentiating points in favour of oncocytoma}

Oncocytoma is common in young age group, mostly asmptomatic. Contrast enhanced CT scan shows Stellate scar (figure;16) and angiogram shows spoke wheel pattern[13,14].

Role of FNAC /Core biopsy in diagnosing oncocytoma; core biopsy increases the diagnostic accuracy of percutaneous biopsy .Immunostains like Vimentin and Glutathione s-transfarese can be used in biopsy tissue for diagnosis of oncocytoma as they are $100 \%$ sensitive and $100 \%$ specific[15].

Role of frozen section biopsy; frozen section biopsy is less sensitive in differentiating the eosinophilic appearance of oncocytomas from eosinophilic variant of RCC hence frozen section should not be used to guide surgical strategy[1].

\section{Conclusion:}

RCC in young adult is biologically and histologically different from RCC in older adult and also have different clinical behavior and long term outcome. Sometime dilemma remains in the inability to confidently differentiate between variant of RCC in young adult and renal oncocytoma, fat poor angiomyolipoma and renal pseudotumor on clinical or radiographic testing. Immunostains like Vimentin, Glutathione s-transfarese, epithelial cell adhesion molecule can be used to differentiate RCC from onocytoma in young adult. Young patients with the RCC should also be evaluated for genetic predispositions and hereditary syndromes such that management and surveillance strategies can be optimize for long-term outcomes.

\section{References}

1. Wein, A., Kavoussi, L., Partin, A. and Peters, C. Campbell-Walsh urology. 11th ed. Philadelphia, PA: Elsevier, 2016: p.1304-1306.

2. Taccoen X, Valeri A, Descotes J, Morin V, Stindel $E$, Doucet $L$ et al. Renal Cell Carcinoma in Adults 40 Years Old or Less: Young Age is an Independent Prognostic Factor for Cancer-Specific Survival. European Urology. 2007;51(4):980-987.

3. Rodriguez A, Patard JJ, Lobel B. Renal cell carcinoma in young adults: incidence, disease outcome and review of the literature. Arch Esp Urol. 2002;55:969-975

4. Daugherty M, Bratslavsky G. Renal Cell Carcinoma in Young Patients: a Review of Recent Literature. Current Urology Reports. 2015;16(2).
5. Suh J, Oak T, Ro J, Truong L, Ayala A, Shen S. Clinicopathologic Features of Renal Cell Carcinoma in Young Adults: A Comparison Study with Renal Cell Carcinoma in Older Patients. Int J Clin Exp Pathol. 2009;2(5):489-493.

6. Mohsin R, Hashm A, Sultan G, Shehzad A, Mubarak M, Ghazanfar N et al. Renal Tumors in Young Adults A Single-Center Experience From a Developing Country. UROLOGY JOURNAL. 2012;9(1):373-380.

7. Abou El Fettouh H, Cherullo E, El-Jack M, Al Maslamani Y, Novick A. Sporadic renal cell carcinoma in young adults: presentation, treatment, and outcome. Urology. 2002;60(5):806810.

8. Agnihotri S, Kumar J, Jain M, Kapoor R, Mandhani A. Renal cell carcinoma in India demonstrates early age of onset \& a late stage of presentation. Indian J Med Res. 2014;140(5):624-629.

9. Wahal S, Gulati A, Biswas B. Renal oncocytoma: A diagnostic dilemma on cytology. Journal of Cytology. 2014;31(1):59.

10. Maatman T, Novick A, Tancinco B, Vesoulis Z, Levin $\mathrm{H}$, Montie $\mathrm{J}$ et al. Renal Oncocytoma: $\mathrm{A}$ Diagnostic and Therapeutic Dilemma. The Journal of Urology. 1984;132(5):878-881.

11. Renshaw A. Subclassification of renal cell neoplasms: an update for the practicing pathologist. Histopathology 2002;41(4):283-300.

12. Weiss LM, Gelb AB, Medeiros LJ. Adult renal epithelial neoplasms. Am J Clin Pathol 1995; 103(5):624-35.

13. Davidson AJ, Hayes WS, Hartman DS, et al. Renal oncocytoma and carcinoma: failure of differentiation with CT. Radiology 1993;186(3):693-6.

14. Licht MR, Novick AC, Tubbs RR, et al. Renal oncocytoma-clinical and biological correlates. J Urol 1993;150(5):1380-3.

15. Liu L, Qian J, Singh H, et al. Immunohistochemical analysis of chromophobe renal cell carcinoma, renal oncocytoma, and clear cell carcinoma: an optimal and practical panel for differential diagnosis. Arch Pathol Lab Med 2007;131(8):1290-7. 